\title{
ADMINISTRAÇÃO DE MEDICAMENTOS INJETÁVEIS POR VIA INTRAMUSCULAR: CONHECIMENTO DOS OCUPACIONAIS DE FARMÁCIAS*
}

\author{
ADMINISTRATION OF INTRAMUSCULAR INJECTIONS MEDICATIONS: \\ KNOWLEDGE OF OCCUPATIONALS WORKING IN PHARMACIES
}

\author{
Silvia Mara Rangel** \\ Silvia Helena De Bortoli Cassiani***
}

RANGEL, S. M; CASSIANI, S. H. De B. Administração de medicamentos injetáveis por via intramuscular: conhecimento dos ocupacionais de farmácias. Rev.Esc.Enf.USP, v. 34, n. 2, p..138-44, jun. 2000.

\section{RESUMO}

Complicações advindas da aplicação incorreta das injeções intramusculares podem acarretar sérios prejuizos orgânicos, favorecer o aparecimento de infecções e aumentar a permanência do paciente na instituição ou prejudicar as funções no trabalho. Estudo anterior detectou vários casos de pacientes com complicações locais após aplicação intramuscular de diclofenaco sódico em farmácias e concluiu que a falta de conhecimento da técnica de administração desse medicamento pode ter sido uma das causas das complicações. Diante disso o estudo atual teve o objetivo de identificar e avaliar o nivel de conhecimentos de ocupacionais que administram medicamentos injetáveis intramusculares à população, em farmácias de Ribeirão Preto - SP. O estudo se constituiu num levantamento, a partir de um questionário contendo 20 questões abertas e fechadas, aplicado a uma população constituída por ocupacionais atuando em farmácias, selecionadas através do método da amostragem simples casual estratificada - partilha proporcional, resultando num total de 41 sujeitos. Concluímos que a população vem recebendo medicamentos injetáveis de ocupacionais com déficit de informações a respeito da técnica de aplicação de injetáveis. Os sujeitos referiram não receber treinamento adequado para exercer esse procedimento, terminando por aprendê-lo com outro funcionário ou observando alguém que o realize. Disto resulta lacunas de conhecimento em uma amostra de ocupacionais que podem, realmente, levar ao aparecimento de complicações pós injeções intramusculares na população que utiliza os serviços desses estabelecimentos.

PALAVRAS-CHAVE: Farmácias. Injeções intramusculares. Medicamentos.

\begin{abstract}
Complications from the incorrect administration of intramuscular injections can cause serious organic damages, infections and increase the patient's permanence in health institution or to harm the functions in the work. The previous study detected several cases of patients with local complications after administration of diclofenac in pharmacies and it concluded that the lack of knowledge of this technique can be the causes of these complications. This current study objectives to identify and evaluate the level of knowledge of the professional that administer medications in pharmacies of Ribeirão Preto - SP. The study constituted in a survey, from a questionnaire with 20 open and closed questions, applied to a population constituted for occupational working in pharmacies, selected through the method of the sampling, resulting in a total of 41 pharmacies. It was concluded that the population is receiving medications from occupationals, without a specific formation and with deficit of knowledge regarding the technique. The subjects referred not to receive training to exercise that procedure, learning it with other employee or observing somebody that accomplishes it. It results knowledge gaps that can cause complications in the population that uses the services of those institutions.
\end{abstract}

KEYWORDS: Pharmacy. Injections intramusculares. Drugs.

\section{INTRODUÇÃO}

A técnica de administração de medicamentos século, era delegada aos profissionais médicos. pela via intramuscular, na primeira metade deste Posteriormente, as enfermeiras também passaram

\footnotetext{
* $\quad$ Projeto subsidiado pela FAPESP, através do auxilio Bolsa Iniciação Científica.

** $\quad$ Discente do $8^{\circ}$ semestre de Graduação da EERP-USP.

*** Orientadora, Prof ${ }^{a}$ Dr. ${ }^{a}$ do Departamento de Enfermagem Geral e Especializada/ EERP-USP.
} 
a desenvolvê-la, e em um curto espaço de tempo, várias pessoas iniciaram o exercício desta técnica, nem sempre com o preparo e conhecimento necessários.

É essencial, além do conhecimento do procedimento técnico, também compreender as ações da medicação para administrá-la de forma a incrementar seu efeito terapêutico e evitar ou minimizar seus efeitos colaterais. O conhecimento científico aplicado a esse procedimento enfatiza o fato de que há locais selecionados e apropriados para aplicação a fim de reduzir o desconforto e possiveis complicações ao paciente e que devem, portanto, ser conhecidos e respeitados.

Estudo de CASSIANI; RANGEL (1997) identificou vários casos de complicações pósinjeções intramusculares em pacientes que receberam Diclofenaco de sódio ${ }^{\circledR}$, nas regiões deltoidea e dorso-glúteo. Os estudos de casos revelaram várias injeções que haviam sido aplicadas em farmácias, resultando para os pacientes em dor tardia, formação de abcessos, hematomas, nodulações e infecções. Alguns pacientes necessitaram de hospitalização ou tratamento ambulatorial até a cicatrização da lesão provocada no músculo e pele.

Agrava-se o fato de que em muitas farmácias no país os medicamentos são administrados sem prescrição médica, sem a supervisão do farmacêutico ou outro profissional com saber nessa área e muitas vezes, não é exigido, dos ocupacionais nenhum curso de nível médio, é o próprio balconista quem administra medicamentos injetáveis, embora seja de competência exclusiva do farmacêutico.Possivelmente a falta de conhecimento tem levado ao aparecimento de ocorrências adversas ou complicações pós-injeções intramusculares.

MENDES et al (1988) reconheceram em seu estudo a falta de preparo dos ocupacionais de farmácia que administram medicamentos injetáveis, sendo esta uma problemática que afeta a população em geral e envolve o papel educativo do enfermeiro - seja porque o enfermeiro deve cumprir o seu papel de educador para promover a saúde, ou porque a administração de medicamentos é de sua competência e responsabilidade.

A literatura explora muito pouco o aspecto da formação daqueles que administram medicamentos na população. O estudo de MENDES et al (1988) foi o único, especificamente, relacionado ao ocupacionais de farmácia na enfermagem e embora a literatura na área de farmácia aborde a problemática dos medicamentos de forma ampla e geral nada foi observado sobre a formação de farmacêuticos na administração de medicamentos injetáveis.
Assim, a enfermagem pode e deve continuar divulgando e realizando investigações sobre a temática Administração de Medicamentos, já que essa é também uma função de sua competência e responsabilidade. A formação profissional do enfermeiro contempla o conteúdo de Administração de Medicamentos de forma a capacitá-lo para a identificação de problemas, para o ensino e supervisão de profissionais atuando nesse fim.

Esses aspectos discutidos acima aliado aos resultados advindos de estudo anterior com complicações pós injeções intramusculares motivaram a realização dessa investigação

\section{OBJETIVO}

Este estudo teve o objetivo de identificar e avaliar o nivel de conhecimento de ocupacionais de farmácias atuando em estabelecimentos de Ribeirão Preto-SP.

\section{METODOLOGIA}

Essa investigação trata-se de um levantamento de informações "survey", utilizando a técnica de obtenção dos dados através de um questionário contendo perguntas fechadas e abertas.

\section{População}

A população alvo foi determinada como sendo constituída por indivíduos que executassem a técnica de administração de injeções intramusculares em farmácias do município de Ribeirão Preto-SP e que concordassem em colaborar com a pesquisa.

\section{Amostra}

A amostra constituiu dos ocupacionais que atuam em uma parcela das farmácias de Ribeirão Preto -SP.

Essa amostra foi constituída a partir de uma lista de 236 farmácias credenciadas e fornecidas pelo Sindicato dos Proprietários de Farmácias de Ribeirão Preto-SP. Destas, foram excluídas 16 farmácias que eram localizadas em outros municipios próximos à cidade e uma que não apresentava o endereço completo, restando 219 estabelecimentos.

Face a este número relativamente alto para a coleta de dados, o procedimento da amostragem simples casual estratificada- partilha proporcional para a seleção de uma amostra foi empregada. Segundo BERQUO et al. (1981) pode-se utilizar a amostragem estratificada nos casos em que o 
pesquisador deseja que subpopulações sejam representadas na amostra com a mesma proporcionalidade com que compõem a população total. Dessa forma, preconizamos o número (n) de 45 farmácias por ser uma quantidade acessivel, para os pesquisadores, na distribuição dos questionários, dada a distância geográfica entre as mesmas. O fator de seleção foram os prefixos dos números telefônicos de cada estabelecimento, já que estes indicam regiões diferentes da cidade e assim uma demanda diferente de população atendida. Determinamos dessa forma que os prefixos corresponderiam ao tamanho de cada extrato populacional $\left(\mathrm{N}_{\mathrm{h}}\right)$.

Os prefixos telefônicos da cidade de Ribeirão Preto - SP são em número de 17. De uma amostra de 219 estabelecimentos (N) obtivemos uma representação com a mesma proporção para cada prefixo no total dos números telefônicos presentes na lista.
A fórmula utilizada na amostragem simples casual estratificada foi:

$$
\begin{aligned}
\mathrm{n}_{\mathrm{h}}= & \mathrm{n} \cdot \frac{\mathrm{N}_{\mathrm{h}}}{\mathrm{N}} \\
& \text { Onde: } \\
& \mathrm{N}_{\mathrm{h}}=\text { é o tamanho de cada extrato populacional } \\
\mathrm{N} & =\text { é o tamanho da população } \\
\mathrm{n} & =\text { é o tamanho total da amostra } \\
& \mathrm{n}_{\mathrm{h}}=\text { é o tamanho da mostra do extrato } \mathrm{h} \text { (que }
\end{aligned}
$$
é o que pretende-se chegar)

Fonte: BERQUÓ, E.S.; SOUZA, J.M.; GOTTIEB,S.L.D. Bioestatística. São Paulo, EPU, 1981.

O quadro a seguir indica a distribuição dos prefixos e as respectivas quantidades de telefones amostrados, após o cálculo do tamanho amostral.

Quadro 1: Distribuição dos prefixos e respectivas quantidades de telefones amostrados:

\begin{tabular}{|l|l|l|l|l|l|l|l|l|l|l|}
\hline Prefixo & $\mathbf{6 1 0}$ & $\mathbf{6 2 2}$ & $\mathbf{6 2 3}$ & $\mathbf{6 2 4}$ & $\mathbf{6 2 5}$ & $\mathbf{6 2 6}$ & $\mathbf{6 2 7}$ & $\mathbf{6 2 8}$ & $\mathbf{6 2 9}$ & Total \\
\hline $\begin{array}{l}\mathbf{N}^{\circ} \mathbf{d e} \\
\text { telefones }\end{array}$ & 17 & 16 & 9 & 14 & 33 & 13 & 8 & 10 & 3 & 123 \\
\hline Prefixo & $\mathbf{6 3 0}$ & $\mathbf{6 3 3}$ & $\mathbf{6 3 4}$ & $\mathbf{6 3 5}$ & $\mathbf{6 3 6}$ & $\mathbf{6 3 7}$ & $\mathbf{6 3 8}$ & $\mathbf{6 3 9}$ & Total & \\
\hline $\begin{array}{l}\mathbf{N}^{\circ} \mathbf{d e} \\
\text { telefones }\end{array}$ & 8 & 17 & 10 & 16 & 16 & 14 & 11 & 4 & 96 & \\
\hline
\end{tabular}

Tendo o número de farmácias amostradas, analisamos novamente a lista de estabelecimentos farmacêuticos filiadas ao Sindicato das Farmácias de Ribeirão Preto-SP, e escolhemos aleatoriamente, através de sorteio, os 45 estabelecimentos cujos funcionários participariam da coleta de dados, respeitando a proporção entre os prefixos.

\section{A coleta de dados}

Elaboramos um questionário para a coleta de dados, abordando os itens relacionados ao conhecimento da administração de medicamentos por via intramuscular, segundo a literatura. Este questionário foi aplicado através de um teste piloto, em cinco alunos bolsistas de iniciação científica, cursando o $7^{\circ}$ semestre do curso de Graduação em Enfermagem. Após as mudanças sugeridas decidimos aplicar os questionários em farmácias para um segundo teste piloto, em cinco ocupacionais. Após o instrumento ser considerado definitivo, partimos para a coletá dos dados.

\section{Procedimentos Éticos}

Para aplicação do instrumento de coleta de dados explicávamos aos sujeitos: que se tratava de um trabalho de pesquisa cujo objetivo consistia em avaliar e identificar o conhecimento dos ocupacionais de farmácias sobre a administração de medicamentos injetáveis, que sua identidade seria mantida em sigilo e que poderia não responder caso não desejasse. Após a concordância verbal e a explicitação das dúvidas relatadas acima, o instrumento era entregue ao funcionário e aguardávamos o seu preenchimento. Em todos os locais visitados, os participantes foram receptivos, manifestaram interesse pela pesquisa, queixaram que são raros cursos sobre o tema e nos interrogaram em que os resultados dessa pesquisa influenciariam o seu cotidiano do trabalho. Caso o farmacêutico responsável estivesse no estabelecimento, a ele também era explicado o objetivo e a finalidade da pesquisa. 


\section{RESULTADOS E DISCUSSÃO}

Foram visitadas 45 farmácias e entrevistados 41 ocupacionais sendo 10 do sexo feminino e 31 do sexo masculino. Durante as visitas, embora mais de um funcionário pudesse participar do estudo, obtivemos as informações, geralmente do funcionário mais experiente, com mais tempo de trabalho e que era indicado pelos outros para responder às questões. Em quatro farmácias os funcionários não responderam, alegando que o proprietário não se encontrava no local no momento, e que não tinham autorização para tal.

Discorremos, a seguir, os dados obtidos categorizando os resultados segundo as questões apresentadas no questionário.

\section{Preparo para administração de medicamentos}

\section{Lavagem das mãos:}

Ao serem questionados sobre qual a primeira atividade a ser feita ao se aplicar uma medicação foram apresentados 5 itens: conectar a agulha na seringa, fazer a antissepsia com algodão e álcool no local da aplicação, fazer a desinfecção da ampola e lavar as mãos $83 \%$ dos entrevistados responderam que o correto é lavar as mãos, enquanto os demais, $12 \%$ referiram que todas as alternativas estavam corretas. Houve $5 \%$ de respostas em branco.

Embora a maioria tenha assinalado o item correto, não eram esperados erros nesta questão, uma vez que tem se divulgado com freqüência que a lavagem das mãos é a primeira atitude ao se efetuar qualquer atividade em relação ao paciente. Deixar de implementar algo tão primordial põe em risco a segurança biológica do paciente.

A lavagem das mãos constitui uma maneira importante de prevenir a propagação de infecções e deve ser realizada antes e depois de qualquer procedimento assistencial que envolva o cliente. $\mathrm{O}$ fato dos ocupacionais não realizarem a lavagem das mãos antes de procedimentos invasivos implica no risco de haver contaminação em alguma fase da preparação da medicação que poderá acarretar em abscesso séptico local no paciente (CASSIANI; RANGEL, 1997).

PILLANS; O'CONNOR (1995) relatam complicações sérias devido a injeções de analgésicos e anti-inflamatórios, como necrose de pele e tecido adiposo além de fascite necrosante. Nas lesões foram isolados Streptococcus pyogenes, Streptococcus faecalis e Escherichia coli sugerindo contaminação, sendo que alguns pacientes desenvolveram septicemia.
Diante de fatos como este, ressalta-se a importância da lavagem das mãos, da antissepsia, da limpeza do local onde se realizam as aplicações e a esterilização do material utilizado para introdução da medicação, evitando assim contaminações. A lavagem das mãos deve ser a fase inicial dos procedimentos.

\section{Conhecimentos de Anatomia:}

\section{a) Seleção dos Locais}

Segundo ATKINSON; MURRAY (1995) as medicações podem ser injetadas em quatro locais básicos: os músculos deltóide e vasto lateral, regiões ventro e dorso glútea. Refere que a delimitação é feita a partir de estruturas anatômicas, desta forma a localização exata do local onde a medicação deve ser administrada exige conhecimentos de anatomia.

Assim, procedemos ao questionamento dos músculos possiveis de aplicação de injeções intramusculares. Obtivemos 40\% (18) das respostas mencionando os músculos deltóide e glúteo, 24,4\% (11) as regiões deltoidea, dorso, ventro glutea e face antero lateral da coxa, 22,2\%(10) citaram os músculos glúteo direito e esquerdo, face antero lateral da coxa e deltóides direito e esquerdo; 2,2\%(1) não respondeu a questão e 2,2\%(1) mencionaram que todos os locais onde há massa muscular desenvolvida é apropriado para se realizar injeções intramusculares.

Estes dados confirmaram que deltóide e glúteo são os locais mais conhecidos. A alusão freqüente ao músculo deltóide denota o desconhecimento deste como o local menos indicado para aplicação de injeções. Segundo ATKINSON; MURRAY(1995) o músculo deltóide é um músculo pequeno, com vasos e nervos que devido a sua superficialidade tem maior probabilidade de serem lesados. CASSIANI; RANGEL (1997) informaram que segundo a literatura, o maior número de complicações pós injeções intramusculares ocorre nos membros superiores.

Frente ao questionamento sobre se conheciam e aplicavam medicações em outros músculos além do deltóide e glúteo, obtivemos $58,5 \%$ respostas positivas(24), 34\% negativas(14), $2,4 \%$ ambígua (assinalaram sim e não) (1) e $5,1 \%$ respostas (2) foram positivas mas não justificaram-na. Destes dados pode-se dizer que mais da metade da população entrevistada, ainda não conhece outros locais de aplicação de medicamentos por via intramuscular além do deltóide e glúteo, demonstrando uma lacuna de conhecimentos quanto .a seleção dos locais. 
Das 24 respostas positivas, 19 sujeitos citaram a coxa como local apropriado para aplicação de injeções porém muitos não sabiam como delimitá-la, 4 responderam a face antero lateral da coxa, 2 mencionaram ventro glúteo e 1, incorretamente, o lado interno da coxa.

Esse último dado só vem acrescentar que o ventro glúteo continua sendo praticamente desconhecido como local disponivel para aplicação, considerando que dentre 41 ocupacionais de farmácia, apenas 2 citaram a região ventroglútea.. Embora seja da região de menor risco de lesão de vasos e nervos, tal fato ocorre por se tratar de uma técnica pouco divulgada no país e que necessita de orientação e treinamento adequados sobre a delimitação do local de introdução da agulha.

A região antero lateral da coxa foi a mais citada dos locais alternativos, porém o fato dos entrevistados referirem não saber delimitá-la, pode denotar que essa região não está sendo utilizada, e se está os ocupacionais não estão sabendo delimitá-la.

\section{b) Classificação dos locais}

Referente à ordem de prioridade dos locais mais seguros para se aplicar injeções, encontrouse as seguintes porcentagens de respostas: músculos ventro e dorso glúteo, antero lateral da coxa e deltóide, $71,1 \%$; músculos deltóide, dorso e ventro glúteo, coxa $15,5 \%$; nenhuma das alternativas anteriores, 6,7\% respostas em branco, 6,7\%. Assim $71,1 \%$ das respostas estavam corretas indicando o músculo ventro-gluteo como o local mais indicado e o deltóide como o menor indicado.

ATKINSON; MURRAY(1995) relatam ser a região ventro glútea um excelente local para aplicação de injeções intramusculares, pois não há grandes vasos sangüineos que podem ser lesados e seu tecido adiposo é menos espesso que o do glúteo. Em seguida, é citada a região dorso glútea, vasto lateral e por fim o músculo deltóide. Este último não deve ser muito utilizado por estar muito próximo ao nervo radial.

Em estudo sobre reações adversas após injeções intramusculares, MÜLLER-VAHL (1985) relatou que o quadrante lateral-superior da nádega é uma região muito ampla e que contém vasos e nervos na sua porção medial, que poderiam se lesados. Este autor sugere uma área mais adequada: glúteo máximo, lateral à espinha iliaca superior ou face lateral da coxa (músculo vasto lateral) por abrigarem um número menor de vasos e nervos.

Um dado que nos chamou a atenção foi o fato da maioria dos entrevistados responder corretamente sobre a ordem de escolha dos locais de aplicação de injeções; entretanto, apesar de conhecerem essa região tem dificuldades em delimitá-la e de aplicar medicamentos nesse local.

\section{c) Locais mais comuns:}

Questionados sobre o local que aplicavam os medicamentos com mais frequência, 21 responderam que o local mais comum para as injeções intramusculares é o glúteo; para 17 é o deltóide e somente 3 responderam ventro-glúteo.

Entre os motivos para a escolha do glúteo foram respondidos: é menos doloroso, tem maior massa muscular, é menos perigoso, é a preferência dos pacientes, tipo de medicação específica, para evitar inchaço, por ser a região mais indicada, onde se pode dar injeções profundas e que a musculatura está relacionada ao menor risco de lesão.

Sobre o deltóide, justificaram dizendo: a maioria das pessoas não aceitam outro local que não seja aquele a que estão acostumados, há os fatores vergonha e o cultural envolvidos, é o local de preferência, há medicações que não são específicas para o glúteo, a maioria das prescrições são de $3 \mathrm{ml}$ e por isso podem ser dadas neste local com exceção de contraceptivo e antibiótico.

Sobre o ventro-glúteo informaram ser devido às características da medicação, porque o risco é menor e tem massa muscular suficiente.

\section{d) Estruturas Nervosas:}

Na questão sobre qual estrutura nervosa poderia ser lesada se houvesse uma limitação adequada nas nádegas, $83,2 \%$ (30) sujeitos responderam o nervo ciático, 7,4\% (5) sabiam da existência de um, nervo mas não sabiam seu nome, 4,2\% (3) não sabiam que existia um nervo e $4,2 \%$ (3) assinalaram a alternativa que mencionava o nervo circunflexo.

Estudo de VILLAREJO; PASCUAL (1993) relata 370 casos de crianças que sofreram injúria do nervo ciático por injeção inapropriada na região do músculo glúteo. Mencionaram que as lesões ocorreram devido a ação mecânica da agulha causando trauma direto no nervo, contração do membro secundária a reação local e dano direto à fibra nervosa pela neurotoxicidade química do agente introduzido. Os pacientes podem nestes casos tornarem-se portadores de paralisia e apresentarem alteração da sensibilidade de membros, além de diminuição da força motora.

Assim, 15,8\% dos entrevistados demonstraram lacuna de conhecimento sobre a principal estrutura nervosa que pode ser lesada caso a agulha seja introduzida em local incorreto e desta forma desconhecem os ocupacionais de farmácias não demostraram conhecer os meios de como evitar possiveis complicações ocasionadas pela lesão do nervo ciático ou outras reações locais. 


\section{e) Volume Injetado:}

Sobre o conhecimento relacionado ao volume de medicamento injetado em cada músculo, 53,6\% (22) pessoas responderam até $4 \mathrm{ml}$, enquanto $37 \%$ (15) colocaram $5 \mathrm{ml}$ em todos os músculos e um colocou $4 \mathrm{ml}$ no deltóide, $5 \mathrm{ml}$ no glúteo e ventro glúteo e $3 \mathrm{ml}$ na coxa; 9,4\% (2) não responderam.

$\mathrm{O}$ volume máximo a ser injetado nos músculos é bastante controvertido entre os autores, mas baseado em ATKINSON; MURRAY (1995), mais de $45 \%$ dos ocupacionais informaram incorretamente, já que $4 \mathrm{ml}$ é o volume máximo a ser injetado em grandes músculos. Segundo GREENBLAT; ALLEN (1978) se um volume maior que o determinado como limite for injetado, poderá comprimir vasos e nervos decorrendo em dor e aumento da temperatura local, hiperemia, além de outras reações mais graves como necrose e alteração da sensibilidade e mobilidade do membro.

O volume de medicamento injetado está relacionado ao músculo escolhido para realização da aplicação e a característica da droga a ser introduzida. O deltóide é considerado um músculo pequeno, conveniente, portanto, para receber doses pequenas de medicação, ou seja até $3 \mathrm{ml}$; enquanto o dorso glúteo, consegue absorver até $5 \mathrm{ml}$, embora seja aconselhável dividir essa dose desse volume em dois locais diferentes.

\section{Procedimentos na Administração de Medicamentos Injetáveis}

\section{a) Aspiração do Êmbolo:}

Toda a amostra investigada respondeu corretamente que ao introduzir a agulha no músculo deve-se aspirar o êmbolo para verificar se nenhum vaso foi atingido antes de injetar a medicação.

$\mathrm{O}$ ato de aspirar o êmbolo da injeção antes de injetar o medicamento possibilita identificar se algum vaso sangüíneo foi atingido pela agulha. Tal procedimento diminui a possibilidade de injeção intravenosa ou intra-arterial de medicamento, evitando dessa forma a ocorrência de vasoespasmos e embolias e consequentemente a necrose tecidual. Outro fator causal pode ser a injeção de substâncias trombogênicas na luz do vaso acarretando uma trombose local (GIOVANETTI et al 1993).

\section{b) Rodizio de locais de aplicação de injeções intramusculares em aplicações freqüentes:}

Ao serem questionados sobre se as injeções devem ser aplicadas num mesmo local, 92,4\% (38) indivíduos responderam negativamente enquanto que $7,6 \%$ (3) justificaram ser correto, e que em uma mesma região pode se aplicar várias vezes.

Entre as justificativas das respostas negativas, $28,6 \%$ (10) deixaram em branco e os demais responderam: 28,6\% (10) para não causar lesões musculares como necrose, caroço e hematoma; 14,3\% (5) para diminuir o risco de infecção, evitar hematoma e porque quanto maior a freqüência de aplicações em um mesmo local torna-o mais dolorido; 8,57\% (3) devese fazer o rodizio para evitar irritações do local após repetidas aplicações; e as demais foram referências isoladas de que, varia de pessoa para pessoa de acordo com a massa muscular, deve-se considerar as condições de saúde do paciente, o paciente sentirá mais dor se não for feito o rodízio e a absorção se torna mais lenta, para descansar o músculo de uma aplicação e outra, para evitar desconfortos e finalmente para melhor absorção do medicamento.

Injeções repetidas em um mesmo local, aumentam a probabilidade de reações tanto pela invasão mecânica da agulha quanto pelas características e volume da medicação depositada no músculo. O rodízio de locais de aplicação poupa o paciente evitando dores e hematomas causados por repetidas injeções em uma mesma região.

Segundo COCKSHOTT et al (1982), lesões podem ocorrer devido a concentração, ph da medicação e natureza química da droga após repetidas injeções em um mesmo local. Nestes casos a absorção fica provavelmente alterada. $O$ fato é que injeções intramusculares causam danos teciduais que progridem para fibroses e demais complicações, agravada pela aplicação freqüentemente em um mesmo local.

\section{c) Complicações pós injeções IM:}

Dos entrevistados $70 \%$ (29) responderam já terem se deparado ou terem conhecimentos da ocorrência de complicações pós injeções. A média de tempo de trabalho dos que já conheciam complicações foi de 19,3 anos; os 29\% (12) restantes disseram desconhecer o assunto e 1\% (1) nada respondeu, dos que não conheciam o assunto foi de 12,8 anos. Os tipos de complicações citadas foram: hematomas, abscessos, necrose, inchaço, aparecimento de nódulos, reação alérgica, choque anafilático, tontura, hipotensão, lesão de estrutura nervosa, náusea, febre e desmaio.

Foi solicitado que os entrevistados que relatassem acidentes ou complicações que conheciam: 55,5\% (25) responderam negativamente, 1 não se lembrava e os $31 \%$ (15) demais citaram os seguintes acidentes: $7,3 \%$ (3) citaram reação alérgica a penicilina (choque anafilático), 7,3\% (3) mencionaram aspiração de sangue antes de injetar a medicação,4,8\% (2) mencionaram a formação de hematoma, atingiu o osso 
com a agulha, entortou a agulha durante a injeção devido a movimentação do paciente, aplicando penicilina a agulha entupiu várias vezes, desmaio, queda de pressão arterial, uma medicação intravenosa foi administrada intramuscular.

Foi ainda questionado se tinham alguma dúvida na técnica e caso tivessem com quem solucionavam. Nenhum ocupante mencionou ter dúvidas sobre a técnica, porém muitos pediram explicação sobre como se procede a delimitação da área ventro-glútea e a antero lateral da coxa. Em caso de apresentarem alguma dúvida 56\% (23) solucionam-na com o próprio farmacêutico, 24,4\% (10) consultam livros, 7,3\% (3) procuram amigos de trabalho, 4,8\% (2) procuraram cursos oferecidos por uma empresa privada, 4,8\% (2) nada responderam e 2,4\% (1) indicou médico ou enfermeira que são membros da família.

\section{CONSIDERAÇÕES FINAIS}

A maioria (83\%) dos ocupacionais entrevistados indicaram que a lavagem das mãos é a primeira atividade a ser realizada na administração de medicamentos injetáveis, não conhecem outros locais de aplicação de medicamentos por via intramuscular além do deltóide e do glúteo. A região ventro-glútea e face ântero-lateral da coxa são praticamente pouco utilizadas; $83,2 \%$ dos entrevistados citaram que o nervo ciático é uma estrutura nervosa que pode ser lesada se houvesse uma limitação inadequada nas nádegas e apontaram a região glútea como a mais comum, na injeção de medicamentos.

Identificou-se, ainda, que os sujeitos que citaram outras regiões para introdução de medicamentos como a face lateral da coxa, não sabiam como delimitá-la corretamente para proceder aplicação. Em relação ao volume de medicação a ser injetada, observou-se que aproximadamente, a metade dos sujeitos não fizeram a relação correta entre a estrutura muscular e a quantidade adequada de medicamento que poderia ser injetada. Assim, a preocupação recai sobre aqueles entrevistados que embora apliquem medicações tem déficit de conhecimentos importantes e que podem estar dificultando a aplicação correta do medicamento.

Os ocupacionais se queixaram da ausência de cursos preparatórios para o desempenho da técnica de administração de injeções. Sabemos que em muitos casos, a aprendizagem ocorre por observação de outros colegas de trabalho mais experientes que transmitem as informações necessárias.

Assim concluímos que há ainda uma parcela de ocupacionais carecem de conhecimentos básicos principalmente aqueles relacionados aos locais mais seguros. A preocupação reside naquele grupo que desconhece aspectos básicos como a delimitação de locais, o que- pode agravar possiveis complicações.
Em farmácias a pessoa qualificada para aplicação de medicamentos é o farmacêutico, estando portanto destituído dos ocupacionais esta função. Consequentemente é direito do paciente exigir que este procedimento seja realizado pelo profissional capacitado, ou que os ocupacionais realizem cursos que os qualifiquem como técnicos e possuam dessa forma a devida autorização para desenvolverem a técnica de aplicação de injeções.

Sem dúvida o enfermeiro pode atuar junto ao grupo de farmacêuticos fornecendo a estes informações atualizadas sobre o procedimento de administração de medicamentos. Essa atuação pode se dar através de cursos de curta duração, participando nos cursos desse conteúdo no ensino de graduação em farmácias e realizando pesquisas conjuntas sobre a administração de medicamentos. Essas iniciativas terão por objetivo capacitar aqueles que estão aplicando medicações na maioria da população.

A partir desse estudo seria interessante desenvolver outro realizando a observação "in loco" dos procedimentos da aplicação de medicamentos injetáveis. Ainda pode ser analisado o conhecimento de farmacêuticos sobre a técnica e qual a fonte de obtenção desse conhecimento.

\section{REFERÊNCIAS BIBLIOGRÁFICAS}

ATKINSON, L.D.; MURRAY, M.E. Fundamentos de enfermagem: introdução do processo de enfermagem. Rio de Janeiro, Guanabara, 1995.

BERQUÓ, E.S. et al. Bioestatística. São Paulo, EPU,1981.

CASSIANI, S.H.De B.; RANGEL, S.M. Causas, conseqüências e reações pós injeções intramusculares em adultos: revisão bibliográfica e estudo de caso, 1997.

COCKSHOTT, W.P. et al. Intramuscular or intralipomatous injection? N. Engl. J. Med., v. 307, n.6, p.356-8, 1982.

GIOVANNETTI, M. et al. Necrose tecidual; efeito colateral do diclofenaco de Sódio, relato de casos e discussão da fisiopatologia. Rev. Hosp. Clín. Fac. Med. S. Paulo, v.48, n.1, p.39-42, 1993.

GREENBLATT, D.; ALLEN, M.D. Intramuscular Injection - site complications. J.Am.Med. Awards, v.240, n. 6, 542-4, 1978.

MENDES, I.A.C. et al. A administração de injetáveis em farmácias: ação educativa do enfermeiro. Rev.Bras.Enf. v.41. n.2, p.93-6, 1988.

MULHER-VAHL, H. Adverse reactions after intramuscular injections. Lancet, v. 1, p. 1050, 1983.

PILLANS, P.I.; O'CONNOR. Tissue necrosis and necrotizing fasciitis after intramuscular administration of diclofenac. Ann. Pharmacother., v.29, p.264-6. 1995.

VILLAREJO, F.J.; PASCUAL, A.M. Injection injury of the sciatic nerve (370 cases). Child's Nery Syst., v.9, p 229-32, 1993. 